中崔佑鎭・尹均德*

水原大學校 環境에너지工學科, *韓國產業技術試驗院

\title{
A Study on Physical Properties of Recyclables obtained from MSW
}

\author{
中Woo Zin Choi and Kun Duk Yoon* \\ Depart. of Environmental and Energy Eng., The University of Suwon \\ * Korea Testing Laboratory
}

요 약

일반적으로 재활용대상 폐자원은 가정에서 분리 배출된 후 재활용선별장에서 수선별에 의해 유가자원으로 회수된다. 그러나 기 존의 재활용선별장에 반입되는 폐자원의 경우 성상이 매우 다양하고 복잡 할 뿐만 아니라 이물질의 함량이 높아 기존의 회수방법 으로는 선별효율이 매우 낮은 실정이다. 따라서 선별장에서 재활용품 회수 후에 발생되는 잔재물은 대부분 매립 또는 소각되고 있 어서 그로인한 2 차환경오염 및 잔류물로부터 추가적인 유가자원의 회수는 시급히 해결해야 할 문제이다. 본 연구에서는 재활용선 별장에 반입되는 폐자원에 대한 성상조사를 실시하여 폐자원의 발생특성 변화를 파악하였으며, 전처리시설의 효율성을 증대시키기 위하여 입도분석을 통하여 향후 재활용 선별시설 구성의 기초자료를 제공하였다.

주제어 : 순환자원, 재활용, 자동화, 물리적 성상, 입도

\begin{abstract}
In general, recyclable items are separately discharged from households and then, hand-sorted into different types of valuables at materials recovery facilities (MRF). However, most of residues after hand-sorting are finally end up with landfill and/or incineration due to lack of separation technologies and economical reasons. In the present study, physical properties on recyclable items obtained from an MRF are investigated to improve the recovery of valuable items. The results of physical compositions based on the sizing tests are also presented.
\end{abstract}

Key words : recyclable, sorting, recycling, physical property, sizing

\section{1. 서 론}

경제규모의 확대와 산업구조의 고도화, 소비자들의 다 양한 구매욕구 등으로 폐기물이 급격히 증가하고 있다. 또한, 대량생산, 대량공급 체제에 따른 물량증가와 과대
포장, 새롭고 다양한 소재의 포장용기의 등장과 신제품 의 출현, 상품의 수명단축 등으로 폐기물의 질이 다양 해지고 발생량 또한 엄청나게 증가하고 있다. 이렇게 발 생한 각종 폐기물이 다시 이용되지 못하고 마구 버려지 고 있어 일차적으로 소중한 자원을 낭비할 뿐만 아니라

\footnotetext{
* Received : October 4, 2012 - Revised : October 16, $2012 \cdot$ Accepted : October 22, 2012

†Corresponding Author : Woo Zin Choi (E-mail: wzchoi@suwon.ac.kr)

Department of Environment and Energy Engineering, The university of suwon, San 2-2, Wau-ri, Bongdam-eup, Hwasung-si, Gyeonggi-do, 445-743, Korea

Tel : +82-31-229-8126 / Fax : +82-31-222-4684

(C) The Korean Institute of Resources Recycling. All rights reserved. This is an open-access article distributed under the terms of the Creative Commons Attribution Non-Commercial License (http://creativecommons.org/licenses/by-nc/3.0/), which permits unrestricted non-commercial use, distribution and reproduction in any medium, provided the original work is properly cited.
} 
환경의 오염과 생태계 파괴에 의한 인류 생존의 위협, 쓰레기 매립지 조성에 따른 지역 갈등 등 바람직하지 않은 각종 사회적 문제를 야기하고 있는 실정이다. 자 원화시설은 일반적으로 매립 방식에서 재활용이 가능한 폐자원은 우선적으로 회수하여 물질 재활용하고, 에너 지화가 가능한 모든 폐기물을 최대한 활용하여, 궁극적 으로는 이산화탄소 $\left(\mathrm{CO}_{2}\right)$ 의 발생을 저감시켜 녹색성장 구현에 크게 이바지 하고 있다.

폐기물의 효과적인 관리를 위해서는 폐기물의 성상과 특징을 잘 파악하여 그에 맞는 방법으로 처분하여야 한 다. 폐기물의 물리적 특성은 폐기물관리 및 처리 대책 수립에 기본적인 자료이다. 폐기물의 효과적인 처리와 관 리 방안을 제시하고 장래대책을 수립하기 위해서는 폐기 물의 물리적 조성이 우선적으로 조사 되어야 한다.

국내 지자체선별장의 경우 분리 - 배출된 폐자원 중 재활용에 부적합 물질의 함량(유가물, 대형폐기물류 등) 이 높아 재활용품 회수율이(60\%미만) 매우 낮은 실정 이다. 특히, 선진국에서 많이 사용되고 있는 발리스틱, flip-flop 등 전처리 장치는 여전히 해외의존도가 높고 국내기술 개발이 시급하다. 특히 안산시, 용인시, 수원 시 등 일부 지자체 선별장에 준 자동화 시설이 설치되 어 있으나 전처리 부분의 자동화 설비가 미비하여 수선 별이 주를 이루고 있을 뿐 아니라 주요 품목만을 선별 회수함으로써 선별효율이나 회수품목의 순도 및 다양화 가 매우 부족한 실정이다.

본 연구에서는 재활용 선별시설에 반입되는 폐자원에 대한 성상조사를 실시하여 폐자원의 발생특성 변화를 파악하였으며, 전처리 시설의 효율성을 증대시키기 위 하여 입도분석을 통해 향후 재활용 선별시설 구성의 기 초자료를 제공하고자 한다.

\section{2. 실험방법}

\section{1. 시료채취}

본 연구는 선별시설에 반입된 재활용폐기물을 대상으 로 총 3 개 지점에서 유리병류 총 $40,194 \mathrm{~g}$, 플라스틱류 총 $67,290 \mathrm{~g}$ 을 마대자루와 비닐봉지에 담겨진 상태와 일부는 파봉 되어 흩어져 있는 폐자원을 무작위로 채취 하여 물성분석을 실시하였다.

시료를 유리병류와 플라스틱류로 구분한 이유는 해당 재 활용선별장이 유리병류와 플라스틱류를 분리하여 반입한 후 각기 다른 선별라인에서 분리선별하고 있었기 때문이다. 무작위로 시료를 채취한 이유는 재활용폐기물의 분리

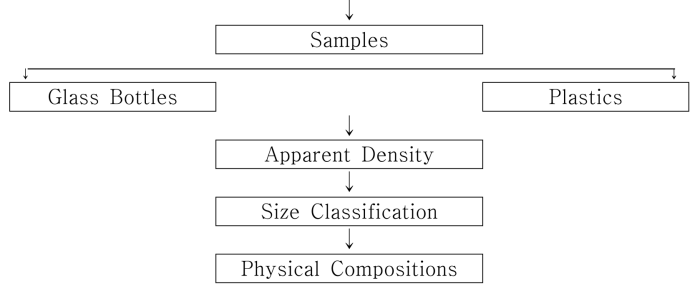

Fig. 1. Experimental procedure.

배출과 수거 및 반입특성상 시점에 따라 물성이 달라진 다. 따라서 이러한 물성의 변화를 고려한 재활용선별시 설을 설계해야 하기 때문에 이런 영향을 살펴보기 위해 혼합하지 않고 채취지점을 달리하여 무작위로 시료를 채 취한 것이다. 실험은 Fig. 1과 같은 절차로 수행하였다.

\section{2. 분석방법}

2.2.1. 입도분석

입도분석은 발생된 생활폐기물의 크기를 고려하여 트 롬멜, 즉 원통형 스크린을 $200 \mathrm{~mm}, 150 \mathrm{~mm}, 100 \mathrm{~mm}$, $80 \mathrm{~mm}, 50 \mathrm{~mm}, 30 \mathrm{~mm}$ 및 $10 \mathrm{~mm}$ 이하 타공 된 것들 을 7단계로 사용하였다. 트롬멜의 운전조건 및 크기분 류는 분류폐기물의 선별효율을 최대화하기 위하여 장치 의 $1 / 3$ 정도씩 시료를 여러 차례 투입하여 실험하였다. 트 롬멜의 속도는 $16 \mathrm{rpm}$ 으로 설정하였으며 구동 시간은 2 3 분으로 하였다. 끈이나 긴 막대기처럼 크기구분이 일정치 않은 폐기물은 스크린을 통과함에 따라 구분하였다.

겉보기 밀도는 폐기물공정시험방법에 따라 부피를 정 확히 알고 있는 용기에 시료를 담고 $30 \mathrm{~cm}$ 높이에서 3 회 낙하시킨 후 표시된 눈금보다 시료의 높이가 낮아지 면 시료를 표시된 눈금까지 채운 후 $30 \mathrm{~cm}$ 높이에서 다시 떨어뜨리는 조작을 반복하여 눈금의 변동이 없을 때까지 시료를 채워 무게를 측정하여 구하였다.

시료량이 너무 적거나 겉보기 밀도 측정이 불가능한 경우에는 생략하였다. 시료량이 많은 것은 $110 \mathrm{~L}$ 용기를 사용하여 측정하였고, 시료량이 적은 것은 $20 \mathrm{~L}$ 용기를 사용하여 측정하였다. 겉보기 밀도는 크게 전체 시료의 '총괄 겉보기 밀도', 입도별로 나누어진 시료의 '입도별 겉보기 밀도'로 나누어 측정하였다.

\subsection{2. 물리 - 화학적 성상분석}

반입된 시료는 입도분석 후 입도별 성상분석을 실시 하였다. 물리적 성상분석은 재활용폐기물과 비재활용폐 기물 그리고 협잡물로 분류하였으며, 재활용폐기물은 재 
활용선별장에서 분리 - 선별하는 기준에 따라 캔은 철 및 알루미늄 캔류 등으로 세분류하였고 플라스틱의 경 우 PET, PP, PE, PS, PVC, 혼합폐플라스틱, 비닐류 등 총 7 가지로 세분류하였다. 비재활용폐기물은 음식물, 섬유류 등 가연물 4 가지와 도자기와 돌류 및 폐건전지 등 불연물 2 가지로 세분류 하였으며, 조성분류가 어려 운 작은 사이즈의 협잡물은 트롬멜 장치에 의해 $10 \mathrm{~mm}$ 스크린을 이용하여 분류 하였다.

특히 $30 \mathrm{~mm}$ 이하의 경우 크기가 작아 재활용폐기물을 더 이상 선별하기 어렵고 여러종류의 폐기물이 섞여 있 어 현실적으로 폐기물에너지로 이용할 수 밖에 없기 때 문에 가연물과 불연물 그리고 협잡물로 재분류하였다. 이렇게 분류함으로써 에너지로서의 이용가능성을 판단 해 볼 수 있기 때문이다.

\subsection{3. 유리병류의 분류}

다양한 크기와 종류의 유리병은 색깔별로 선별되어 판매되기 때문에 투명, 청록색, 갈색으로 구분한 후 각 각의 색깔별로 대, 소 및 파손으로 세분류하였다. "대" 는 크기가 220 300 mm인 것들이며, “소"는 크기가 80 120 mm인 병들이며, “파손”은 깨진 병들을 말하며 특이사항은 유리병에 이물질이 들어간 경우로 “음식물 병”으로 분리하였고, 유리병이 아닌 경우는 “도자기 및 돌류"와 “그 외 기타"등으로 분류하였다. Table 1에는 유리병 분류기준을 제시하였다.

\section{3. 실험결과}

\section{1. 총괄시료의 겉보기밀도}

Table 2는 유리병류 3 개와 플라스틱류 시료의 총 겉보기 밀도를 나타내었다. 3 개 시료의 경우 시료 1 $245.43 \mathrm{~kg} / \mathrm{m}^{3}$, 시료 $2253.25 \mathrm{~kg} / \mathrm{m}^{3}$, 시료 $3263.9 \mathrm{~kg} / \mathrm{m}^{3}$ 로 평균 겉보기밀도는 $254.19 \mathrm{~kg} / \mathrm{m}^{3}$ 으로 나타났다.

플라스틱의 경우 시료 $153.6 \mathrm{~kg} / \mathrm{m}^{3}$, 시료 $246.5 \mathrm{~kg} / \mathrm{m}^{3}$,
시료 $342 \mathrm{~kg} / \mathrm{m}^{3}$, 평균 $47.4 \mathrm{~kg} / \mathrm{m}^{3}$ 로 플라스틱류와 유리병 류를 비교하였을 때 약 5 배 이상의 차이를 보였다.

\section{2. 플라스틱류 구성비}

Table 3은 플라스틱류 시료의 크기별 무게와 구성 비

Table 1. Classification of glass bottles

\begin{tabular}{|c|c|}
\hline Bottles & Classification \\
\hline \multirow{4}{*}{ Transparent } & Large $(220 \sim 300 \mathrm{~mm})$ \\
\cline { 2 - 2 } & Small $(80 \sim 120 \mathrm{~mm})$ \\
\cline { 2 - 2 } Green & Broken \\
\cline { 2 - 2 } & Large $(220 \sim 300 \mathrm{~mm})$ \\
\cline { 2 - 2 } & Small $(80 \sim 120 \mathrm{~mm})$ \\
\hline \multirow{3}{*}{ Brown } & Broken \\
\cline { 2 - 2 } & Large $(220 \sim 300 \mathrm{~mm})$ \\
\cline { 2 - 2 } & Small $(80 \sim 120 \mathrm{~mm})$ \\
\hline \multirow{3}{*}{ Others } & Broken \\
\cline { 2 - 2 } & Bottles with food \\
\cline { 2 - 2 } & Ceramics \& Stones \\
\hline
\end{tabular}

Table 2. Apparent densities of test samples

\begin{tabular}{|c|c|}
\hline Classification & Apparent Density $\left(\mathrm{kg} / \mathrm{m}^{3}\right)$ \\
\hline Bottles sample\# 1 & 245.4 \\
\hline Bottles sample\# 2 & 253.3 \\
\hline Bottles sample\# 3 & 264 \\
\hline Average & 254.2 \\
\hline Plastics sample\# 1 & 53.6 \\
\hline Plastics sample\# 2 & 46.5 \\
\hline Plastics sample\# 3 & 42 \\
\hline Average & 47.4 \\
\hline
\end{tabular}

Table 3. Weight and ratio for plastics based on size classification

\begin{tabular}{|c|c|c|c|c|c|c|}
\hline Item & Size $(\mathrm{mm})$ & Weight(g) & Ratio(\%) & Size $(\mathrm{mm})$ & Weight(g) & Ratio(\%) \\
\hline \multirow{4}{*}{$\begin{array}{c}\text { Average for } 3 \\
\text { samples }\end{array}$} & $>200$ & 8,782 & 13.05 & $>50$ & 17,176 & 25.53 \\
\cline { 2 - 7 } & $>150$ & 5,767 & 8.57 & $>30$ & 4,206 & 6.25 \\
\cline { 2 - 7 } & $>100$ & 19,564 & 29.07 & $>10$ & 1,485 & 2.21 \\
\cline { 2 - 7 } & $>80$ & 9,750 & 14.49 & $<10$ & 560 & 0.83 \\
\cline { 2 - 7 } & Total & \multicolumn{7}{|c|}{67,290} & 100 \\
\hline
\end{tabular}

J. of Korean Inst. Resources Recycling Vol. 21, No. 5, 2012 
율의 평균값을 나타내었다. 시료 1 은 $22,284 \mathrm{~g}$, 시료 2 는 $20,274 \mathrm{~g}$, 시료 3 은 $24,732 \mathrm{~g}$ 으로 총 $67,290 \mathrm{~g}$ 시료 를 분석하였다.

$100 \mathrm{~mm}$ 와 $50 \mathrm{~mm}$ 의 시료의 경우는 대부분 PET병, 용기 등과 요구르트병과 같은 재활용 대상 폐기물의 비 율이 높다. 크기별 시료 분석결과 PET병 뚜껑의 분리 배출이 원활하게 이루어지지 않아 PET병 뚜껑의 선별 결과가 다르게 나타났다.

Table 3에서 알 수 있듯이 입도별 시료의 구성비는
$100 \mathrm{~mm}$ 및 $50 \mathrm{~mm}$ 가 각각 $29.07 \%$ 및 $25.53 \%$ 로 비 교적 높게 나타났다. 그에 반해 $150 \mathrm{~mm}$ 초과와 $30 \mathrm{~mm}$ 초과 및 그 이하 크기의 경우는 $10 \%$ 가 넘지 않는 것으로 조사되었다.

\section{3. 입도별 성상분석}

Table 4는 총 시료에 대한 성상분석 결과를 요약한 표이다. 표에서 알 수 있듯이 재활용 폐기물과 비재활 용 폐기물을 구분하여 분류하였을 때 재활용 폐기물은

Table 4. Weights of the physical compositions based on size classification

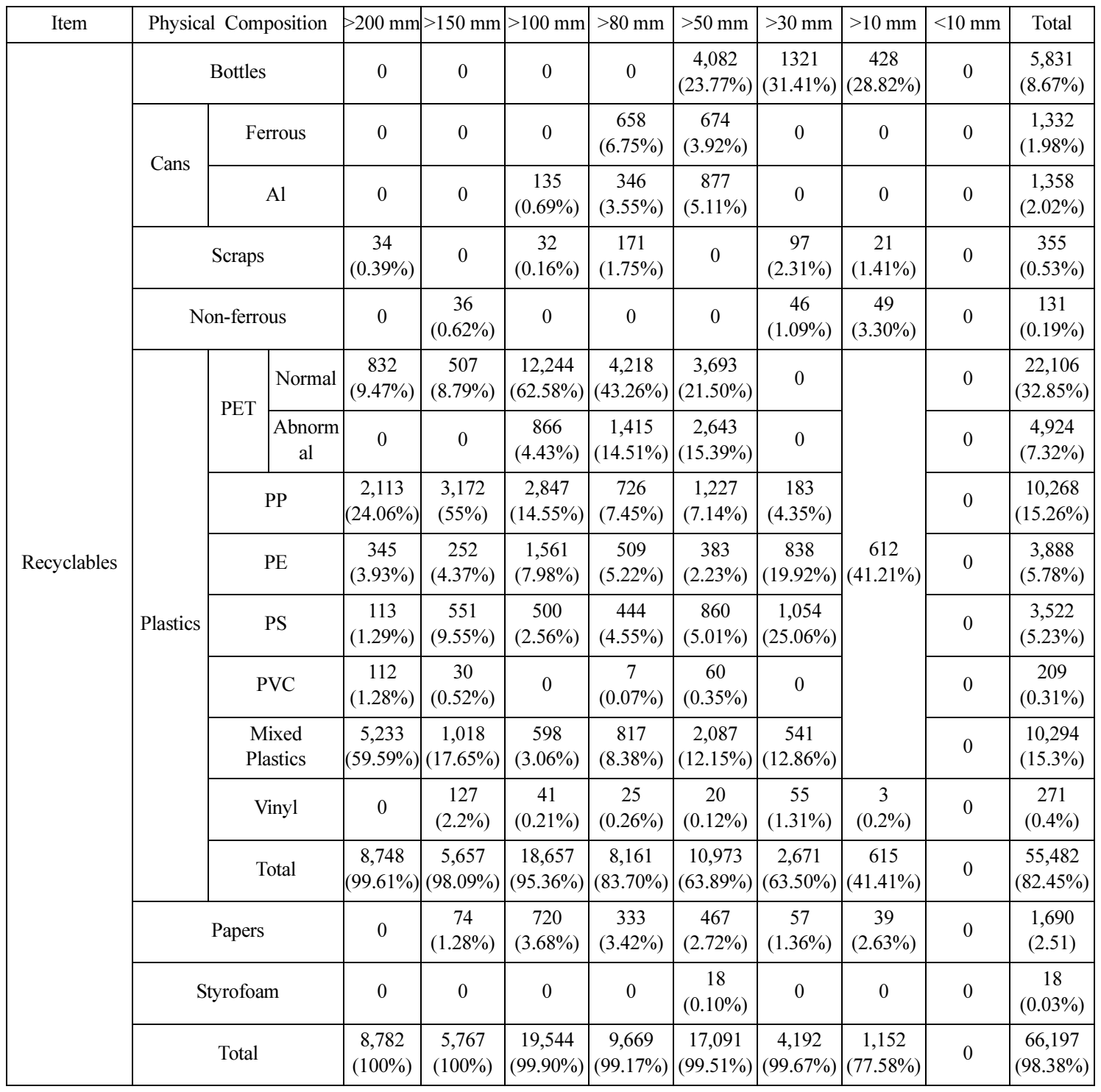


Table 4. Continued

\begin{tabular}{|c|c|c|c|c|c|c|c|c|c|c|c|}
\hline Item & \multicolumn{2}{|c|}{ Physical Composition } & $>200 \mathrm{~mm}$ & $>150 \mathrm{~mm}$ & $>100 \mathrm{~mm}$ & $>80 \mathrm{~mm}$ & $>50 \mathrm{~mm}$ & $>30 \mathrm{~mm}$ & $>10 \mathrm{~mm}$ & $<10 \mathrm{~mm}$ & Total \\
\hline \multirow{7}{*}{$\begin{array}{c}\text { Non- } \\
\text { Recyclables }\end{array}$} & \multirow{4}{*}{$\begin{array}{l}\text { Combu } \\
\text {-stibles }\end{array}$} & Food & 0 & 0 & 0 & 0 & 0 & 0 & $\begin{array}{c}32 \\
(2.15 \%)\end{array}$ & 0 & $\begin{array}{c}32 \\
(0.05 \%)\end{array}$ \\
\hline & & Fiber & 0 & 0 & $\begin{array}{c}20 \\
(0.1 \%)\end{array}$ & $\begin{array}{c}81 \\
(0.83 \%)\end{array}$ & $\begin{array}{c}50 \\
(0.29 \%)\end{array}$ & $\begin{array}{c}14 \\
(0.33 \%)\end{array}$ & $\begin{array}{c}46 \\
(3.1 \%)\end{array}$ & 0 & $\begin{array}{c}211 \\
(0.31 \%)\end{array}$ \\
\hline & & Wood & 0 & 0 & 0 & 0 & $\begin{array}{c}31 \\
(0.18 \%)\end{array}$ & 0 & $\begin{array}{c}104 \\
(7 \%)\end{array}$ & 0 & $\begin{array}{c}135 \\
(0.2 \%)\end{array}$ \\
\hline & & Rubber & 0 & 0 & 0 & 0 & $\begin{array}{c}4 \\
(0.02 \%)\end{array}$ & 0 & 0 & 0 & $\begin{array}{c}4 \\
(0.01 \%)\end{array}$ \\
\hline & \multirow{2}{*}{$\begin{array}{c}\text { Incom } \\
\text {-bustibles }\end{array}$} & $\begin{array}{c}\text { Ceramics \& } \\
\text { Stones }\end{array}$ & 0 & 0 & 0 & 0 & 0 & 0 & 0 & 0 & 0 \\
\hline & & Waste Battery & 0 & 0 & 0 & 0 & 0 & 0 & $\begin{array}{c}34 \\
(2.29 \%)\end{array}$ & 0 & $\begin{array}{c}34 \\
(0.05 \%)\end{array}$ \\
\hline & \multicolumn{2}{|r|}{ Total } & 0 & 0 & $\begin{array}{c}20 \\
(0.1 \%)\end{array}$ & $\begin{array}{c}81 \\
(0.83 \%)\end{array}$ & $\begin{array}{c}85 \\
(0.49 \%)\end{array}$ & $\begin{array}{c}14 \\
(0.33 \%)\end{array}$ & $\begin{array}{c}216 \\
(14.55 \%)\end{array}$ & 0 & $\begin{array}{c}416 \\
(0.62 \%)\end{array}$ \\
\hline \multicolumn{3}{|c|}{ Impurities } & 0 & 0 & 0 & 0 & 0 & 0 & $\begin{array}{c}117 \\
(7.88 \%)\end{array}$ & $\begin{array}{c}560 \\
(100 \%)\end{array}$ & $\begin{array}{c}677 \\
(1 \%)\end{array}$ \\
\hline \multicolumn{3}{|c|}{ Total } & $\begin{array}{c}8,782 \\
(100 \%)\end{array}$ & $\begin{array}{c}5,767 \\
(100 \%)\end{array}$ & $\begin{array}{l}19,564 \\
(100 \%)\end{array}$ & $\begin{array}{c}9,750 \\
(100 \%)\end{array}$ & $\begin{array}{l}17,176 \\
(100 \%)\end{array}$ & $\begin{array}{c}4,206 \\
(100 \%)\end{array}$ & $\begin{array}{c}1,485 \\
(100 \%)\end{array}$ & $\begin{array}{c}560 \\
(100 \%)\end{array}$ & $\begin{array}{l}67,290 \\
(100 \%)\end{array}$ \\
\hline
\end{tabular}

약 $98.38 \%$ 이고 비재활용 폐기물은 $0.62 \%$, 협잡물은 $1.01 \%$ 이다. 재활용 폐기물 중 플라스틱류가 $82.45 \%$ 로 가장 많은 양을 차지하고 있고, 플라스틱 재질별로는 PET $32.85 \%$ 으로 가장 높았으며, 다음으로 혼합플라스 틱 $15.3 \%, \mathrm{PP} 15.26 \%$ 의 순으로 나타났다. PET의 특 이사항은 PET용기 내에 물이 들어 있거나 음식물이 들어있는 경우도 약 $7.32 \%$ 로 비교적 높게 나타나서 풍 력선별 등 비중선별 기술을 적용할 경우 선별효율에 영 향을 미칠 것으로 사료된다.

플라스틱류 외의 폐기물로는 유리병류 $8.67 \%$, 캔류 $4 \%$ 의 비율로 비재활용계 폐기물은 성상별로 구성 비율 이 매우 낮았다.

크기별 성상 구성비는 각 크기별로 비교적 플라스틱 류가 가장 높게 차지하고 있으며, $200 \mathrm{~mm}$ 와 $150 \mathrm{~mm}$ 초과에는 혼합플라스틱, $100 \mathrm{~mm}, 80 \mathrm{~mm}$ 및 $50 \mathrm{~mm}$ 초 과에는 $\mathrm{PET}, 30 \mathrm{~mm}$ 초과에는 $\mathrm{PE}, \mathrm{PS}$ 가 가장 높은 비 율을 보이고, 8 종류의 크기종류에서 비재활용 폐기물은 $30 \mathrm{~mm}$ 초과에서만 높은 비율을 보였다.

비재활용 폐기물 중 가연물과 불연물과의 비율을 보 면 가연물이 $91.83 \%$ 이고 불연물이 $8.17 \%$ 로 가연물의 함량이 높고 섬유와 목재류의 비율이 가장 높았으며, 협 잡물은 $10 \mathrm{~mm}$ 초과에서는 $10.88 \%, 10 \mathrm{~mm}$ 이하에서는 $100 \%$ 비율이 확인되었다.

J. of Korean Inst. Resources Recycling Vol. 21, No. 5, 2012

\section{4. 유리병류 성상별 시료 무게 및 구성비}

유리병류는 투명, 청록색 및 갈색으로 분류하였으며, 각 색깔별로 대·소와 파손, 특이사항 등 4종류로 세분 류하였다. Table 5는 유리병류 시료전체에 대한 성상별

Table 5. Weight and ratio for bottles

\begin{tabular}{|c|c|c|c|}
\hline \multicolumn{2}{|r|}{ Bottles } & Weight(g) & Ratio(\%) \\
\hline \multirow{3}{*}{ Transparent } & Large (大 ) & 5,138 & 12.78 \\
\hline & Small (小 ) & 9,387 & 23.35 \\
\hline & Broken & 1,995 & 4.96 \\
\hline \multirow{3}{*}{ Green } & Large (大 ) & 7,819 & 19.45 \\
\hline & Small ( 小) & 4,782 & 11.90 \\
\hline & Broken & 1,229 & 3.06 \\
\hline \multirow{3}{*}{ Brown } & Large (大 ) & 1,934 & 4.81 \\
\hline & Small ( 小) & 3,032 & 7.54 \\
\hline & Broken & 2,902 & 7.22 \\
\hline \multirow{3}{*}{ Others } & Food & 551 & 1.37 \\
\hline & Ceramics \& Stones & 302 & 0.75 \\
\hline & Others & 1,122 & 2.79 \\
\hline \multicolumn{2}{|r|}{ Total } & 40,193 & 100.00 \\
\hline
\end{tabular}

Large : 220 300 mm, Small : 80 120 mm 
무게 및 구성비를 나타낸 표이다.

유리병류의 성상별 구성비는 투명 대(大) $12.78 \%$, 투 명 소(小) $23.35 \%$, 파손 $4.96 \%$ 이고 청록색의 경우 대(大) $19.45 \%$, 소(小) $11.90 \%$, 파손 $8.07 \%$ 로 각각 조사되었 으며, 갈색의 경우 각각 대(大) $4.81 \%$, 소(小) $13.97 \%$, 파손 $7.22 \%$ 이며 특이사항은 총 $4.91 \%$ 이다. 투명과 갈색의 경우는 소(小) 크기의 병이 가장 많았고 청록색 은 대(大) 크기의 병의 비율이 높았다.

성상결과에서 나타나 있듯이 유리병은 재활용 선별장 반입 시 많은 양이 파손되어 반입되기 때문에 인력선별 시 부상의 위험은 물론 선별효율이 떨어질 수 있기 때 문에 자동선별시스템의 도입이 필요하다 판단된다.

\section{4. 결 론}

본 연구에서는 재활용 선별시설에 반입되는 폐기물의 유리병류 40,194 g, 플라스틱류 $67,290 \mathrm{~g}$ 을 각각 채취하 여 크기분포 및 물리적 조성특성에 대한 분석을 수행하 였으며, 다음과 같은 결론을 얻었다.

1. 재활용 선별시설에 반입되는 폐기물은 비닐봉투나 마대자루에 담겨져 반입 되는데 선별시설을 자동화 할 경우 담겨져 있는 폐기물에 대한 파봉장치의 도입이 필 요할 것으로 판단된다.

2. 플라스틱류 시료의 구성비를 보면 $200 \mathrm{~mm}$ 와 $150 \mathrm{~mm}$ 초과에서 플라스틱 중 혼합플라스틱에 대한 비 율이 높았으며, 혼합플라스틱은 플라스틱의 자동선별장 치인 광학선별장치의 적용에 어려움을 줄 수 있기 때문 에 상대적으로 크기가 큰 폐기물은 미리 제거하여 선별 장치에 투입하는 방법이 고려되어야 할 것으로 판단된다.

3. 플라스틱류 시료에 대한 성상분석 결과 재활용 폐 기물이 $98.38 \%$, 비재활용 폐기물은 $0.62 \%$ 로 재활용 폐 기물 비율이 월등히 높았으며, 특히 재활용 폐기물 중 플라스틱류의 비율이 가장 높았으며, 또한 이중 PET 비율이 가장 많이 분포 되어 있다. PET 용기류 중 음 식물이나 물이 들어 있어 선별장치에 영항을 줄 수 있 는 특이사항도 $7.32 \%$ 에 달하였다.

4. 유리병류를 색깔별로 분류하였을 때 투명과 청록 색 비율이 높고, 크기별 구분 결과 투명과 갈색병의 경 우는 소(小)크기의 병이 많이 분포되어있다. 유리병류는 비중이 무겁고 파손 때문에 취급과 저장이 용이하지 않 기 때문에 플라스틱류와 혼합하여 분류하는 것보다 우 선적으로 별도 분류하고, 파손으로 인하여 인력에 의한
수선별시 부상의 위험이 있으며, 또한 선별효율 등도 크 게 떨어질 수 있기 때문에 자동선별시스템의 도입이 필 요하다 판단된다.

5. 재활용 선별시설의 단위공정 구성 시 반입되는 폐 기물의 특성은 선별장치를 설치 할 때 가장 중요하다. 특히 폐기물의 크기별 성상분석을 통해 폐기물 전처리 장치 구성에 대한기초자료로 활용 할 수 있을 것으로 판단된다.

\section{감사의 글}

본 연구는 환경부의 글로벌탑 환경기술개발사업의 일 환으로 폐금속 - 유용자원재활용기술개발사업단의 연구 비 지원으로 수행되었으며, 이에 감사드립니다.

\section{참고문헌}

1. Choi W. Z., 2011 : Development of Automatic Sorting System for Municipal Recyclable Items, Annual Report, R\&D Center for Valuable Recycling.

2. Seo K. I. et al., 2010 : Investigation on Possibility of Automatic Color Sorting for PET Bottles by Color Recognition; J. of Korea Society of Waste Managements 27(7), pp. 594-599.

3. Cho H. S. et al., 2010 : Estimation of Energy Recovery Potential of Solid Waste Generated from Korea, J. of Korea Society of Waste Management, 27(3), pp. 189-195.

4. Choi W. Z. et al., 2012 : A Study on Physical Properties of Recyclables obtained from MSW, The Korean Institute of Resources Recycling $38^{\text {th }}$ Conference, Proceeding, 5. 1718, Kyungbuk University.

5. Park J-S. et al., 2010 : A Study for Selection of Unit Process and Pre-Sorting Instrument Hole Size Through Analysis on MSW Physical Characteristics of Various District, J. of Korea Society of Waste Management, 27(1), 99 26-34.

6. Yoon K. D. et al., 2012 : Physical Characteristics of Recyclable Items obtained from Materials Recovery Facilities, Proceeding, 2012 Spring Conference of the Korea Society of Waste Management, pp. 295-297.

7. Lee B. S. et al., 2010 : Development of Separation System with Rotating Rakes for Recovery of Film-based Plastics, J. of Korea Institute of Resources Recycling, 19(3), pp. 24-32.

8. Lee B. S. et al., 2009 : Development of Bag Rupturing Device with Octagonal Rotating Blade Drums for MSWs, J. of Korea Institute of Resources Recycling, 18(5), pp. 63-71. 


\section{崔 佑 鎭}

- 현재 수원대학교 환경공학과 교수

- 당 학회지 제9권 1 호 참조

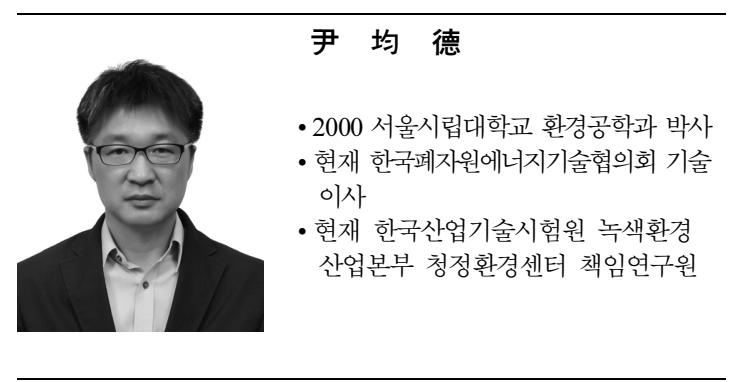

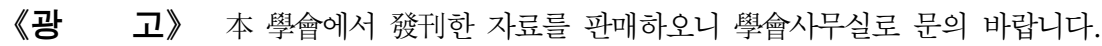

* EARTH '93 Proceeding(1993) 457쪽,

價格 : 20,000 원

(The 2th International Symposium on East Asian Resources Recycling Technology)

* 자원리싸이클링의 실제(1994) 400쪽,

價格 : 15,000 원

* 학회지 합본집 I VIII

價格 : 40,000원, 50,000원(비회원)

(I : 통권 제 1 호 제 10 호, II : 통권 제 11 호 제 20 호, III : 통권 제 21 호 제 30 호, IV : 통권 제 31 제 40 호,

$\mathrm{V}$ : 통권 제 41 호 제 50 호, VI: 통권 제 51 호 제 62 호, VII: 통권 제 63 호 제 74 호, VIII: 통권 제 75 호 제 86 호)

* 한 · 일자원리싸이클링공동워크샵 논문집(1996) 483쪽, 價格 : 30,000 원

* 한 · 미자원리싸이클링공동워크샵 논문집(1996) 174쪽, 價格 : 15,000 원

* 자원리싸이클링 총서I(1997년 1월) 311쪽, 價格 : 18,000 원

*'97 미주 자원재활용기술실태조사(1997년) 107쪽, 價格 : 15,000원

* 日本의 리싸이클링 產業(1998년 1월) 395쪽, 價格 : 22,000원, 발행처-文知社

*EARTH 2001 Proceeding (2001) 788쪽，價格 : 100,000원

(The 6th International Symposium on East Asian Resources Recycling Technology)

* 오재현의 자동차 리싸이클링기행(2003년 2월) 312쪽, 價格 : 20,000원, 발행처-MJ미디어

* 리싸이클링백서(자원재활용백서, 1999년) 440쪽, 價格 : 15,000원, 발행처-文知社

* 리싸이클링백서(자원재활용백서, 2004년) 578쪽, 價格 : 27,000원, 발행처-淸文閣

* 리싸이클링백서(자원재활용백서, 2009년) 592쪽, 價格 : 30,000원, 발행처-淸文閣

*EARTH 2009 Proceeding (2009) 911쪽, 價格 : 100,000원

(The 10th International Symposium on East Asian Resources Recycling Technology) 